\title{
SISTEMA DE GESTÃO AMBIENTAL (ISO 14000) E INDÚSTRIA CANAVIEIRA COM SEUS PASSIVOS AMBIENTAIS
}

\author{
EM ÁREAS DE EXPANSÃo
}

\begin{abstract}
RABELO J.C. ${ }^{1}$; PIETRAFESA J.P. ${ }^{2}$
1. Juliano de Caldas Rabelo: Docente do curso de Administração da Facer Unidade Ceres. Mestre em Sociedade, Tecnologia e Meio Ambiente Unievangélica. Av. Brasil, S/N, Qd. 13 Morada Verde Ceres - Go. CEP: 76.300-000. jrabelo.ria@hotmail.com
\end{abstract}

2. José Paulo Pietrafesa Docente do Programa de Mestrado Sociedade, Tecnologia e Meio Ambiente da UniEVANGÉLICA e Professor da Universidade Federal de Goiás (UFG). ippietrafesa@gmail.com

\section{RESUMO}

A preocupação com o desenvolvimento sustentável e a adoção de gestão ambiental por parte das empresas são temas atuais e muito discutidos. O Brasil é um dos maiores produtores de cana-de-açúcar do mundo. O processo de produção de açúcar e etanol, entretanto, gera consequências que impactam as relações sociais, a economia e o meio ambiente. $O$ objetivo geral da pesquisa visa compreender 0 processo de expansão do setor sucroalcooleiro da microrregião de Ceres. Relaciona-se o processo de expansão com a literatura existente sobre certificações ambientais e sistemas empresariais. As certificações ambientais são instrumentos hábeis, que asseguram às empresas, por meio de chancela de organismo certificador independente, garantir e confirmar o gerenciamento de qualidade técnica e ambiental da produção. Analisam-se, também, dois processos judiciais que uma indústria sucroalcooleira da Microrregião de Ceres respondeu, pelos danos ambientais ocorridos no Rio das Almas, que corta as cidades de Ceres e Rialma, e ainda, pelos prejuízos causados à saúde da população residente no percurso dos caminhões de transporte de cana no município de Carmo do Rio Verde-GO. A pesquisa realizou-se com base na bibliografia referida e classifica-se como descritiva com abordagem qualitativa.

Palavras-chave: Setor sucroalcooleiro, Meio ambiente, Desenvolvimentomento sustentável e Certificações ambientais. 


\begin{abstract}
The preoccupation with sustainable development and the adoption of environmental management inside the companies are actually themes discussed Brazil is one of the biggest manufacturer of sugarcane in the world. The process in manufacturing sugar and ethanol brings consequences that impact the social relations, economy and the environment. The main goal of this research is to comprehend the process of expansion in sugar and ethanol sector in "microrregião de Ceres". The process is related to the literature that exist about environmental certifications and enterprises system. The environmental certifications are important tools that give the companies a way to manage the quality environmental technique of production. It also assay that, two lawsuits an industry of sugarcane "Microrregião de Ceres" replied, because of environmental damage on "Rio das Almas" that crosses Ceres and Rialma and then the damages to the people's health who live on the truck's route in Carmo do Rio Verde-GO. The study was based on bibliography related and classified as descriptive and qualitative.
\end{abstract}

Key Words: sugar and ethanol sector, environment, sustainable development and environmental certifications.

\title{
1 Introdução
}

Os passivos ambientais causados pelo desenvolvimento industrial e econômico do mundo atual geram transtornos para as autoridades, organizações ambientais e à sociedade. Segundo Kraemer (2004) o passivo ambiental representa os danos causados ao meio ambiente, dos quais contradiz com a responsabilidade social.

O setor sucroalcooleiro em alguns casos provoca os mais diversos danos ambientais, que vão desde a preparação do solo, as técnicas de cultivo e os processos produtivos. Admite-se que estas técnicas não são negativas em si, mas o uso indiscriminado de defensivos agrícolas, de fertilizantes causam contaminações do solo e problemas de saúde aos trabalhadores, com a utilização indiscriminada dos recursos hídricos e com o manejo de maquinários sem manutenção, o óleo vaza, emite-se dióxido de carbono contamina-se a água, o ar e o solo. Tais impactos agem de forma negativa e prejudicam o meio ambiente, com a falta de equilíbrio no uso de recursos naturais, que são limitados não há comprometimento com as causas sociais da comunidade.

Diante destes, o presente artigo discutiu a relação entre o sistema empresarial e meio ambiente e, ressaltou a importância de se ter uma política 
ambiental próxima do conceito de sustentabilidade. A pesquisa destacou a importância da sustentabilidade no sistema empresarial e terá como pontos de referência as questões econômicas, sociais e ambientais.

$\mathrm{Na}$ elaboração dessa pesquisa considerou-se como parâmetros fundamentais as certificações da série ISO 14.000 da Organização Internacional de Normatização no qual está implantado o Sistema de Gestão Ambiental (SGA). Este mecanismo tem como objetivo os procedimentos dinâmicos e interativos, que abarcam nas estruturas organizacionais as atividades de planejamento, cargos, práticas, procedimentos, processos e que estabelece a política ambiental de uma organização.

O objetivo geral desta pesquisa foi compreender o processo de expansão do setor sucroalcooleiro, da microrregião de Ceres, relacionando com a literatura existente sobre certificações e preservação ambiental.

Os objetivos específicos expuseram dados existentes sobre a expansão do setor sucroalcooleiro em Goiás e na microrregião de Ceres e avaliam informações públicas da prática empresarial de uma indústria sucroalcooleira instalada em um município da microrregião de Ceres com a legislação ambiental brasileira. Pretendese com este estudo evidenciar as vantagens que a gestão ambiental oferece, no espaço delimitado deste tipo de indústria.

\section{METODOLOGIA}

Para desenvolver o presente estudo utilizou-se da metodologia da pesquisa bibliográfica. Procedeu-se análises de livros, revistas, monografias, dissertações, artigos, jornais e material da internet de fontes seguras em revistas indexadas disponíveis nos sites: Lilacs, SciELO, Medline, Bireme, todos relacionados ao tema. $\mathrm{Na}$ pesquisa bibliográfica não se tem o propósito de repetir o que já foi escrito, porém, busca-se analisar um tema específico com outra abordagem. Trata-se de uma técnica, importante para explorar nova áreas (MARCONI, LAKATOS, 2003).

A classificação da pesquisa é do tipo descritiva com abordagem qualitativa. A pesquisa descritiva admite ao investigador alargar sua experiência em torno de certas dificuldades e perceber com perfeição os fatos e fenômenos da realidade (TRIVIÑOS, 1987). A pesquisa qualitativa pode ser assinalada como a experiência de um entendimento minudenciado dos significados e das características 
situacionais proporcionadas pelos entrevistados, ao invés da produção de medidas quantitativas de características ou de comportamentos. (RICHARDSON, 1999).

Procurou-se evidenciar referenciais teóricos baseados em dados de alguns autores, que discorrem sobre o tema em questão relacionado à empresa denunciada, para explicar a importância da visão crítica sobre sistemas empresariais e promover o desenvolvimento com sustentabilidade ambiental e econômica.

\section{Sistema empresarial e a relação com meio ambiente}

O sistema empresarial é um dos principais fatores do desenvolvimento econômico de um país, pois, seus desenvolvimentos tecnológicos e a grande aptidão de geração de recursos têm a capacidade de fazer com que cada vez mais necessitem de atos cooperativos e agregados capazes de realizar processos, que tem por objetivo atender ao compromisso de precaução de poluição e conformidade legal para manter o foco na melhoria específica. (DIAS, 2002).

Os efeitos negativos da ação do ser humano sobre o meio ambiente são graves e determinam não somente a restauração dos danos, mas, também, exigem a mudança de hábitos e atitudes. O modelo de desenvolvimento que atualmente vivenciamos estimula o consumo irresponsável, principalmente, nas classes sociais de maior poder aquisitivo, o que provoca uma gigantesca pressão referente ao meio ambiente. E esse consumismo insaciável, é a causa fundamental da degradação ambiental. (DIAS, 2002).

Os problemas ambientais passaram a ser discutidos não apenas entre cargos de chefia e diretores das empresas, mas passaram a ser uma preocupação de toda organização empenhada com o desenvolvimento sustentável. (ALEGRIA, 2009).

De acordo com Cordeiro e Ribeiro (2002), quando as empresas começam a ser questionadas e são responsabilizadas pelo efeito ambiental ocasionado pela sua produção, continuam a ignorar as leis e não assumem a responsabilidade com o meio ambiente. Percebe-se que algumas empresas burlam as leis de proteção ambiental, aproveitam as brechas das supervisões dos órgãos governamentais, para 
diminuir os seus custos e, assim, aumentar o seus lucros sem se preocupar com os prejuízos sociais e ambientais.

As empresas devem se adequar ao contexto de sustentabilidade, e compartilhar do entendimento de que possa existir um objetivo comum, e não um conflito entre o desenvolvimento ambiental com o econômico. Medidas de controle e proteção ambiental são necessárias para manter a qualidade de vida no presente e assegurá-lo para as gerações futuras. (MOURA, 2005).

A gestão ambiental da empresa, que é estruturada por meio de departamentos perde a visão a longo prazo sobre os resultados, e passa a ser exclusivamente um grupo voltado para decidir problemas ocasionados à empresa pelo meio ambiente.

Ao ser inserido nas organizações o Sistema de Gestão Ambiental (SGA), desenvolve o potencial competitivo da empresa, pois, a percepção da sociedade brasileira dos problemas ambientais está se desenvolvendo cada vez mais, não apenas por meio de jornais e de televisão, mas também, pela educação ambiental que é ministrada nas escolas e em muitas outras instituições. Assim, como efeito de todo esse desenvolvimento, a atitude da sociedade contemporânea evoluiu gradativamente na aquisição de uma consciência ambiental.

Um SGA traz diversas vantagens para as organizações e o meio ambiente. Dentre as benfeitorias mais citados do SGA, destacam-se:

\footnotetext{
Diferencial competitivo, uma vez que o conhecimento das informações das atividades, produtos e serviços que interatuam com o meio ambiente podem inventar barreiras comerciais para os competidores; minimização de custos, por meio do controle de alguma alteração, adversa ou beneficente, que proceda das atividades, produtos ou serviços da organização; memória organizacional, conglomerando a gestão ambiental sistematizada, a relação da qualidade ambiental à gestão da empresa, a conscientização ambiental dos funcionários e a companhia com a comunidade, com reflexos positivos na imagem da organização; redução de riscos em papel da segurança legal, da segurança das informações, da diminuição dos acidentes e passivos ambientais, da diminuição dos riscos dos produtos e da identificação das vulnerabilidades. (TIBOR e FELDMAN, 2000, p. 77).
}

Os fatores citados acima estimulam as empresas a se certificarem ambientalmente. Além dos mencionados anteriormente, enfatiza-se as barreiras técnicas de mercado, o crescimento da consciência ambiental, pressões de agências financiadoras, pressões de clientes, seguradoras, modernização do sistema de qualidade e a sofisticação do processo produtivo. 


\section{Certificações ambientais: A ISO 14000}

Dentre os diversos instrumentos técnicos e gerenciais de proteção ambiental, empregados pelas empresas e pela sociedade, as certificações ambientais chamam, cada vez mais, atenção. Destaca-se que a ISO 14000, compreende um conjunto de normas ambientais, de caráter voluntário e de âmbito internacional e admite a obtenção da certificação ambiental. A ISO 14000 é uma norma internacionalmente reconhecida e determina o que precisa ser normatizado para constituir um Sistema de Gestão Ambiental (SGA) eficaz. A norma é desenvolvida com objetivo de designar a estabilização entre a manutenção da rentabilidade e a diminuição do dano ambiental; com o comprometimento de toda a organização (ABNT, 2005).

Segundo Zurita (2004), as NBR ISO 14001 e 14004 foram estabelecidas como aderentes às Normas da série NBR ISO 9000, que orientam a prática da qualidade em processos e serviços nas organizações e compartilham princípios comuns de sistemas de gestão.

Sousa (2006) indica que a Certificação ambiental européia Eco-Management and Audit Scheme (EMAS) é um sistema voluntário, o qual agencia o progresso consecutivo do comportamento ambiental das organizações públicas e privadas. A certificação em questão é totalmente compatibilizada com a norma ISO 14001, porém vai mais longe. Entende-se que o EMAS, representa uma abordagem inovada à proteção ambiental por meio do recurso a mecanismos de mercado.

Como exigência, as empresas passaram a agir proativamente em alguns casos antecipando-se a legislação e com adoção de novas estratégias ambientais, que visavam à concepção de novos produtos e de ações voltadas para a proteção ambiental (MOURA, 2005).

Segundo Santos (2008), tal fato induziu à procura pela qualidade ambiental diante de novas tecnologias, iniciativas voluntárias das organizações e modelos de gestão inovadores. Aparecem, assim instrumentos voltados para a corresponsabilidade na gestão ambiental, a exemplo da certificação ambiental. 
ferramenta que tem a capacidade de apresentar resultados efetivos das empresas e constituir-se em valioso instrumento para consolidação da coresponsabilidade, os quais envolvem as empresas e os órgãos de controle ambiental. O processo de certificação tem a capacidade de motivar os funcionários para modificação de atitudes que se cogitam no desenvolvimento de medidas preventivas. (SANTOS, 2008).

Ressalta-se que a questão ambiental vem moldando os comportamentos sociais, porque os consumidores conscientizados almejam produtos que tenham qualidade e responsabilidades sociais e ambientais nos manejos produtivo, com isso as empresas para antederem essa demanda, são forçadas a aderirem às normas, com às da série ISO 14000.

Segundo Valle (2007), a participação brasileira na ISO 14000 se dá através da Associação Brasileira de Normas Técnicas (ABNT), do Grupo de Apoio à Normalização Ambiental (GANA) e do Instituto Nacional de Metrologia, Normalização e Qualidade Industrial (INMETRO).

Os objetivos da ISO 14000 são mencionados por Furtado e Furtado (2010):

\begin{abstract}
Instituir padrões que tem a capacidade de levar a excelência ambiental e deste modo convir de direção para a avaliação do desempenho ambiental; simplificar exigências de registros e selos ambientais e tornar mínima as barreiras ambientais; estabelecer normas universais para a gestão ambiental e estruturar o sistema de gestão ambiental nas organizações; adaptar iniciativas de normalização pelos países.
\end{abstract}

Valle (2007, p. 78) ressalta que a gestão ambiental da ISO 14000 está estruturada em dois grandes módulos, denominados avaliação da organização e avaliação de produtos e processos.

\begin{abstract}
O primeiro módulo da gestão ambiental da ISO 14000 consiste em ser o da avaliação da organização que incide do sistema de gestão ambiental, do balanceamento de performance ambiental e da auditoria ambiental. $\mathrm{O}$ segundo módulo é referente ao balanceamento de produtos e procedimentos que abrange a avaliação do ciclo de vida, a rotulagem ambiental e os aspectos ambientais em normas e produtos.
\end{abstract}

Segundo Valle (2007), as normas da série ISO 14000 não substituem a legislação ambiental vigente no local onde se encontra instalada a organização. As normas do mesmo modo não constituem padrões de desempenho. As mesmas necessitam ser estabelecidos pela própria empresa, nos limites que são equiparados com a política ambiental vigente. 
As normas da série ISO 14000, têm como baseamento o Sistema de Gestão Ambiental as quais formam diretrizes para as auditorias ambientais, avaliações de desempenho ambiental da organização e análise do ciclo de vida dos produtos, aceitando as ações empresariais transparentes quanto aos aspectos ambientais. (VALLE, 2007, p. 93).

Machado (2008, p. 65) afirma que:

A política ambiental não se restringe à eliminação ou diminuição da poluição já existente ou muito elevada proteção contra o perigo, mas faz com que a poluição seja combatida desde o início, a proteção contra o simples risco e que o recurso natural seja desfrutado sobre o baseamento de um rendimento duradouro.

Com tudo, observa-se a necessidade das empresas estabelecerem parâmetros para o espaço ambiental, pois, tal fator revela a necessidade de adaptação aos requisitos descritos nas normas ISO.

\section{Expansão da cana no estado de Goiás e na Microrregião de Ceres-GO}

No atualizado processo de expansão da cana-de-açúcar em Goiás, vê-se um desenvolvimento maior em área plantada na mesorregião sul, lugar onde a maior parte das terras se encontra predominantemente ocupada por agricultura e pecuária. Nessa região verifica-se a disputa por terras em meio à cana-de-açúcar e as áreas de grãos e, secundariamente, a cana-de-açúcar por áreas de pastagem (SILVA e MIZIARA, 2011).

Apesar da produção de cana de açúcar se encontrar presente no estado de Goiás há muito tempo, a área cultivada teve um aumento significativo nos últimos anos e a previsão é de que, por causa desse aumento do consumo de etanol e à necessidade de aumento da produção para poder atender ao crescimento do mercado interno e munir as exportações, mantenha-se o processo de incorporação de novas áreas para a expansão da cultura canavieira em Goiás. (SOUZA e MIZIARA, 2010).

A Companhia Nacional de Abastecimento (CONAB, (2012) no âmbito de um programa de cooperação com o Ministério da Agricultura, Pecuária e Abastecimento (MAPA), realizou entre os dias 05 e 16 de março de 2012, o primeiro levantamento da safra 2012/13 de cana-de-açúcar. Nesta etapa foram visitadas todas as unidades de produção sucroalcooleira em atividade, situadas nos vários estados produtores. A 
lavoura de cana-de-açúcar continua em expansão no Brasil. As áreas em produção continuam com progressivo aumento, Goiás está com 7,9\%, e não há registro de deficiência hídrica para lavoura de cana-de-açúcar. A área cultivada com cana-deaçúcar que será colhida e destinada à atividade sucroalcooleira na safra 2012/13 está estimada em 8.567,2 mil hectares, distribuídos em todos estados produtores conforme suas características. O estado de São Paulo é o maior produtor com $51,66 \%$ (4.426,45 mil hectares), seguido por Minas Gerais com 8,97\% (768,64 mil hectares), Goiás com 8,54\% (732,02 mil hectares). Outra região que apresentou crescimento significativo na área de expansão foi a Centro-Oeste, 188.396 hectares, puxado por Goiás pelo plantio de 115.792 hectares.

Mesmo com a estagnação na produção de etanol, nota-se que ainda continua a expansão das lavouras de cana, devido ao incremento da comercialização do açúcar, como também do potencial enérgico de seus subprodutos, tais como o bagaço.

O MAPA (2012) apresentou no dia 10 de abril de 2012 o primeiro levantamento da safra 2012/13 de cana-de-açúcar, o qual teve como previsão de que o Brasil produzirá 602,18 milhões de toneladas, $5,4 \%$ de aumento ante a temporada 2011/12 --571,44 milhões.

A área estratégica do Estado de Goiás favorece para o progresso do cultivo da cana-de-açúcar, por ter a fertilidade de seus solos passíveis de correção, por ter terrenos com declives admissíveis para a mecanização, ter a qualidade de apresentar disponibilidade de mão-de-obra para as colheitas manuais. Segundo Camargo (2009), a Companhia Nacional de Abastecimento (CONAB/2009), Goiás firma-se a cada ano como uma nova fronteira do setor sucroalcooleiro, sendo que os índices desse setor em Goiás são todos muito superiores aos do País. Na produção, o desempenho goiano foi superior aos índices nacionais, tanto em crescimento do volume de produção quanto em produtividade.

Na região centro oeste brasileiro nos últimos anos, a demanda por etanol aumentou significativamente e assim sendo, a região passou a ser o alvo das indústrias canavieiras que investiram maciçamente na expansão das lavouras, uma vez que se encontra no centro do país e tem fácil ingresso para o escoamento da produção da lavoura (CONAB, 2008). No entanto, para as indústrias canavieiras ampliarem-se houve a precisão de investirem um grande capital, mas nesta expansão não estavam contidos os investimentos em projetos de sustentabilidade social. (CAMARGO, 2009). 
De acordo com os dados obtido no site Canat (2011): no ano de 2005 havia aproximadamente 210.000 hectares de área cultivada, já no ano de 2008 o total de cultivo era de aproximadamente 420.000 hectares, no ano de 2009 o aumento foi bastante significado com quase 600.000 hectares. Portanto em 2010 houve um pequeno aumento na área plantada, saltando para aproximados 620.000 hectares, já em 2011 houve também um pequeno incremento. Percebe-se que a expansão da área foi mais acentuada nos períodos que compreendem os anos de 2005 a 2009, já nos dois últimos anos o crescimento foi ponderado. Mas mesmo assim não houve retração nas áreas cultivadas.

Ainda conforme os dados do site Canasat (2011), nota-se a magnitude da expansão da área cultivada por classe, como também na área disponível para colheita no estado de Goiás, no ano de 2005 havia cerca 216.025 hectares no campo de total para cultivo, já no ano de 2011 há total de 731.981 hectares.

O quadro abaixo demonstra a queda acentuada na área plantada por hectares de alguns produtos agrícolas, em detrimento do aumento da área com cana-de-açúcar nos anos de 2000 a 2011.

Quadro 1: Área colhida (ha) de alguns produtos agrícolas na Microrregião de Ceres-GO - 2000 e 2011.

\begin{tabular}{|c|r|r|r|r|r|}
\hline ANO & ARROZ & FEIJÃO & MILHO & \multicolumn{2}{|l|}{ CANA-DE-AÇÚCAR } \\
\hline 2000 & 13.040 & 4.610 & 33.723 & 25.155 \\
\hline 2011 & 6.440 & 690 & 16.610 & 101.346 \\
\hline
\end{tabular}

Fonte: Disponível em http://www.seplan.go.gov.br/sepin/. Acesso em 24/08/2012

Elaboração: Dados elaborados pelo próprio autor/2012.

Após a análise dos dados acima percebe-se o quanto a produção de outros produtos agrícolas com arroz, feijão e milho tiveram uma acentuada retração na área colhida na microrregião de Ceres, tornando notável a expansão de cultivo da canade açúcar no período de 11 anos.

\section{Passivos Ambientais na Microrregião de Ceres-GO}

Os passivos Ambientais adquiriram maior importância simultaneamente quando a sociedade brasileira abriu os olhos para a preocupação com o 
ecossistema e com o destino que suas cidades, matas, águas e país terão futuramente.

Segundo Palhano e Mafra (2005), essa preocupação recente e a legislação, com o meio ambiente, entretanto, não são suficientes para assegurar que o Brasil seja um país modelo na questão ambiental. O país, ainda, está distante de possuir um padrão ideal de condutas preservacionistas e repressivas indispensáveis porque crimes ambientais de grande repercussão são praticados, quase que diariamente.

Não sendo diferente no interior de Goiás, torna-se relevante a compreensão do processo seguir, do qual cita-se literalmente termos das denúncias movidas pela Promotoria de Justiça da Comarca de Rialma-Goiás contra a indústria instalada na região, que infringiu a legislação ambiental, para posterior análise:

\begin{abstract}
O Ministério Público do Estado de Goiás pelo Promotor de Justiça infraassinado, vem à presença de Vossa Excelência, nos termos do artigo 129, inciso I da Constituição Federal e artigo 24 e seguintes do Código de Processo Penal Brasileiro, fundamentado no Inquérito Policial n. $059 / 2006$, oferecer DENÚNCIA em desfavor da referida indústria, pessoa jurídica de direito privado, inscrita no Cadastro Nacional de Pessoas Jurídicas.(PROMOTORIA DE JUSTIÇA DA COMARCA DE RIALMA-GOIÁS, 2009).
\end{abstract}

Consta dos autos de inquérito policial, que os denunciados, a primeira, sociedade empresária produtora de álcool, o segundo, cotista e administrador da primeira e, o terceiro, diretor técnico da primeira, entre os meses de junho a setembro de 2006, destruíram floresta de preservação permanente, às margens do

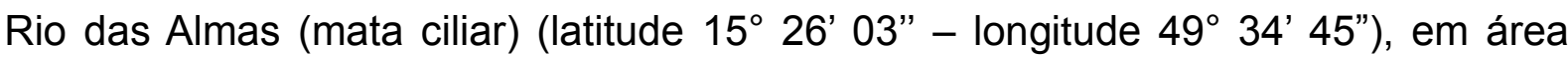
aproximada de $1.265,50 \mathrm{~m}^{2}$ (mil, duzentos e sessenta e cinco metros e cinqüenta centímetros quadrados), situada na Fazenda Formiga, neste município, conforme Laudo de Exame Pericial de folhas 23/33. (PROMOTORIA DE JUSTIÇA DA COMARCA DE RIALMA - GOIÁS, 2009).

Segundo apurado, a pessoa jurídica, sediada na Microrregião de Ceres-GO, dedica-se a atividade de produção de álcool, através do processamento da cana-deaçúcar. Para a obtenção da matéria prima, a denunciada, celebrou diversos contratos de parceria agrícola ou arrendamento rural, com proprietários rurais da região, pagando-Ihes um percentual sobre o valor da cana-de-açúcar produzida, em função da área de terras envolvida no plantio. A preparação do solo, o plantio e a colheita da cana-de-açúcar são realizados por empregados da primeira denunciada, 
utilizando-se de seus equipamentos (tratores, caminhões, implementos agrícolas, etc.) e insumos." (PROMOTORIA DE JUSTIÇA DA COMARCA DE RIALMA GOIÁS, 2009).

De acordo com a Promotoria de Justiça da Comarca de Rialma - Goiás (2009), sem que ocorresse a outorga de direitos de uso de recursos hídricos, houve a instalação de bombas de sucção de água para irrigação da lavoura, bem como foi ausentes os estudos de impacto ambiental e o licenciamento ambiental pelo órgão estadual competente, o terceiro denunciado, diretor técnico da primeira, determinou o início das obras civis no local citado, causado a destruição de floresta nativa, situada em área de preservação permanente (mata ciliar), conforme se depreende do Laudo de Exame Pericial de folhas 23/33.

A outorga dos direitos de uso dos recursos hídricos configura um dos instrumentos mais ressaltante da Programa Nacional de Recursos Hídricos (PNRH). A sua execução permite o controle de todos os usos pelo Poder Público, o qual visa garantir a realização dos objetivos da política com embasamento nos seus fundamentos e respeitando-se as diretrizes totais de ação para a prática. (KELMAN, 2000).

Segundo a Promotoria de Justiça da Comarca de Rialma - Goiás (2009), relatou que do mesmo modo, a referida indústria, tentou extrair recursos minerais (água) do Rio das Almas, na área destruída, sem a devida outorga de direitos de uso de recursos hídricos, pela Secretaria do Meio Ambiente e dos Recursos Hídricos do Estado de Goiás - SEMARH, somente não obtendo êxito em decorrência do embargo judicial das obras do sistema de captação.

Grande problema mundial, da atualidade, diz respeito aos passivos praticados contra o meio ambiente, que se tornam cada dia mais frequentes, e mais danosos e impactantes ao meio ambiente como um todo, e, consequentemente, a toda coletividade, que é a titular do bem ambiental. Com tudo percebe-se que a empresa não adotou uma política de gestão ambiental, não se inteirou sobre a legislação ambiental vigente.

Segundo Copola (2005), no Brasil, esse panorama ensejou a edição da Lei federal oㅜ 9.605, de 12 de fevereiro de 1.998, o chamado Código Penal Ambiental, que sistematizou as leis extravagantes que existiam, sem, contudo, no que seria a melhor técnica, revogá-las expressamente, para apenas revogar disposições em contrário. 
O Ministério Público do Estado de Goiás realizou uma denuncia a empresa:

\begin{abstract}
Como incursos nas penas dos artigos 38 , caput e 55 , caput, ambos da Lei n. $.9 .605 / 1998$ - Lei dos Crimes Ambientais, requerendo que recebida e autuada esta, sejam os denunciados citados para comparecerem ao interrogatório, por si ou por seus representantes legais, sob pena de ser decretada a revelia pelo não comparecimento injustificado e, enfim, para se virem processar até final julgamento e condenação, nos termos dos artigos 394 e 395 e 538 usque 540 do Código de Processo Penal Brasileiro. (PROMOTORIA DE JUSTIÇA DA COMARCA DE RIALMA - GOIÁS, 2009).
\end{abstract}

A denúncia contra a indústria foi recebida em 6 de junho de 2007, consoante decisão de fl. 85. Foram realizados os interrogatórios dos acusados. Foram juntadas as defesas prévias dos acusados e foi colhido o depoimento das testemunhas. (PROMOTORIA DE JUSTIÇA DA COMARCA DE RIALMA - GOIÁS, 2009).

A denúncia é um valioso aliado, especialmente aos crimes causados ao meio ambiente. Assim sendo, tanto a população como os órgãos responsáveis, precisam estar sempre atentos a esses crimes que vem ocorrendo a cada dia mais, sendo não somente em nosso País, mas em todo o mundo. E deste modo à denúncia deve sinalizar mais consciência da sociedade quanto à necessidade da preservação dos recursos naturais.

O Réu juntou aos autos, às fls. 193/204, cópia da licença de Instalação expedida pela Agência Goiana de Meio Ambiente (AGMA), Licença de Funcionamento expedida pela AGMA, Outorgas para a captação e irrigação da área expedida pela Secretaria do Meio Ambiente e dos Recursos Hídricos (SEMARH) e Ofício do instituto Brasileiro do Meio Ambiente e dos Recursos Naturais Renováveis (IBAMA). (PROMOTORIA DE JUSTIÇA DA COMARCA DE RIALMA - GOIÁS, 2009).

Juntadas as folhas de antecedentes criminais atualizadas em nome dos acusados, vieram então os autos com vista. Da análise das provas documentais e testemunhais resultantes da instrução criminal levada a cabo nos presentes autos, verifica-se que restaram exaustivamente provadas a materialidade e a autoria dos delitos narrados na peça vestibular.

De acordo com a leitura realizada sobre o dano ambiental causado pela empresa, entende-se que a mesma tenta conduzir as provas dos autos no sentido de que o executor do projeto de captação de recursos hídricos que ocasionou o dano ambiental descrito na denúncia seria o Condomínio. (Outra empresa). 
A mesma indústria, também foi denunciada pelo transporte que estava sendo realizado todos os dias da semana no período de colheita, durante 24 horas por dia. No intuito de viabilizar um transporte rápido e eficiente entre o local da colheita e a sede da empresa, a mesma construiu um anel viário na cidade de Carmo do Rio Verde e o tem utilizado como caminho para seus veículos. E assim, esse anel viário não é asfaltado. Quando os veículos da ré transitam por ele levantam intensa nuvem de poeira que atinge a comunidade de Carmo do Rio Verde. (TOLEDO, 2006).

Como o trânsito de caminhões é frequente, há uma natural elevação dos níveis de poeira e tal fato, conforme relata a denúncia do ministério público tem prejudicado a saúde da população desta cidade.

Diante desses fatos promotoria de justiça do Carmo do Rio Verde - GO autuou representação em 28 de abril de 2006 e buscou remediar o problema diretamente com a ré.

De acordo com o Art. 225. Todos têm direito ao meio ambiente ecologicamente equilibrado, bem de uso comum do povo e essencial à sadia qualidade de vida, impondo-se ao Poder Público e à coletividade o dever de defendê-lo e preservá-lo para as presentes e futuras gerações.

Não resta dúvida de que uma exposição prolongada à poeira gerada pela atividade da ré gera inúmeros transtornos para a saúde, principalmente para a atividade respiratória. E quem mais sofre com a ausência de cuidados com o meio ambiente são crianças que não têm condições de se defender desses malefícios.

Os danos já consumados só tendem a se agravar, atingindo, se não concedido o provimento judicial requerido, o nível da irreversibilidade, atentando se para o fato de que outros danos poderão surgir, num desdobramento desses ou como fatos danosos novos e independentes, inclusive, ocasionando nas pessoas doenças respiratórias de natureza grave. (PROMOTORIA DE JUSTIÇA DE CARMO DO RIO VERDE, 2006)

De acordo com a Promotoria de Justiça de Carmo do Rio Verde (2006), fundamento no artigo 12 da lei 7347/85, o requer que seja determinada à indústria:

[...] que providencie a rega do anel viário de Carmo do Rio Verde, durante os dias em que utilizá-lo, por meio de caminhão pipa, em intervalos regulares e suficientes para que não seja produzida poeira, garantindo-se um mínimo de 06 (seis) regas diárias, sob pena do pagamento de multa diária de $R \$ 10.000,00$ (dez mil reais). 
A responsabilidade pelos danos causados ao meio ambiente determina ao atuante gerador do prejuízo ao meio ambiente que assuma as consequências de sua ação ou omissão, direta ou indiretamente, referentes aos recursos da natureza, praticando assim, o crime ambiental. (JUCOVSKY, 2000).

Compreendendo a denuncia da Promotoria de Rialma, entende-se que o órgão ministerial que conduz a denúncia contra a referida empresa, entende que a acusada é sim a causadora dos danos descritos na denúncia, a qual praticou o crime de realizar o desmatamento para passagem de uma rede de energia elétrica até chegar à margem do Rio das Almas, para fornecimento de energia elétrica para captação de águas para irrigação de lavoura de cana; "[...] enquanto aguardavam a licença as obras foram iniciadas com desmatamento da área mencionada na denúncia, com área de $1.200 \mathrm{~m}^{2}$; [...]" PROMOTORIA DE JUSTIÇA DA COMARCA DE RIALMA - GOIÁS, 2009).

Deste modo, foi por causa justamente da falta de normas técnicas e guias de condutas responsáveis da empresa pesquisada, que foi provado que a acusada entre os meses de junho a setembro de 2006, desmatou florestas permanentes e tentou extrair recursos minerais (água) sem a devida outorga. (PROMOTORIA DE JUSTIÇA DA COMARCA DE RIALMA - GOIÁS, 2009).

Ressalta-se que a responsabilidade das empresas, ou a falta desta, é motivo de preocupação a todos que tem como desígnio preservar o meio ambiente, assim sendo todos devem estar sempre atentos ao desenvolvimento e ao monitoramento das condições de trabalho ambientais de certas empresas. (ANTUNES, 2006).

Conforme Barbieri (2008), vários crimes ambientais são cometidos nos vários continentes por indústrias dos mais variados setores, e deste modo, observase claramente a necessidade de maior controle, monitoramento e responsabilidade da atividade industrial frente ao meio ambiente.

A consciência ambiental, embora do recente crescimento, ainda não é uma regra entre todos os cidadãos. Pois, acredita-se que uma empresa que possui qualidade, não avançaria contra o Meio Ambiente. E um compromisso com o Meio Ambiente é, acima de tudo, um compromisso com a vida. A certificação pela ISO 14001 é uma provocação e um desafio para a competitividade da organização.

Percebe-se que a referida indústria, praticou um passivo ambiental, na qual destruíram floresta de preservação permanente, às margens do Rio das Almas e 
tentaram extrair recursos minerais (água) do Rio das Almas, sem a devida outorga de direitos de uso de recursos hídricos, a qual fica localizada no município de Rialma - Go. A falta de conscientização da empresa ocasionou vários danos à natureza, entretanto ainda a organização atribui qualquer culpa do plantio desregrado e de forma incorreta, como o presente acontecimento de crime ambiental, todo em cima do condomínio, ficando a acusada sem quaisquer dívidas com a justiça.

Antes de a empresa dar início às questões produtivas que interverem no meio ambiente, poderia ter realizado um diagnóstico completo da ação pretendida, para se evitar esses transtornos com a sociedade e a justiça, da qual acarretou o seguinte requerimento de condenação por parte do ministério público:

\begin{abstract}
O Ministério Público requer a condenação dos acusados, pela prática, da conduta delituosa tipificada no artigo 38, caput, da Lei $n^{\circ}$ 9.605/1998 (Lei dos Crimes Ambientais), e artigo 55, caput, também da Lei $n^{\circ}$ 9.605/1998, devendo ser este último c/c artigo 14 do Código Penal (Tentado). (PROMOTORIA DE JUSTIÇA DA COMARCA DE RIALMA - GOIÁS, 2009).
\end{abstract}

Por fim, os acusados confessaram a prática das condutas delituosas a eles imputadas, deverá ser considerada a incidência da atenuante genérica prevista no artigo 65, inciso III, alínea "d", do Código Penal. (PROMOTORIA DE JUSTIÇA DA COMARCA DE RIALMA - GOIÁS, 2009).

De acordo com Rinaldo Aparecido Barros (2010) juiz de direito vem por meio da ação Pública que o requerente Ministério Público do Estado de Goiás moveu contra o requerido, solicitar informações, o mais breve possível, quanto à possibilidade de se rever as condicionantes apostas na licença ambiental, a fim de que sejam incorporadas as seguintes:

1) Que o empreendedor instale equipamentos para monitorar a vazão do manancial de forma que permita calibrar a curva chave no ponto, disponibilizando as leituras da régua e os resultados das medições de vazão realizadas ao órgão ambiental SANEAGO;

2) Que o empreendedor promova uma compensação ambiental pelos danos causados ao meio ambiente na Fazenda Formiga, conforme descrito no" relatório elaborado pelo técnico Sr. Neri Caetano Barbosa da antiga Agência Ambiental;

3) Que o empreendedor recupere as áreas de preservação permanente degradadas das margens do Rio das Almas e das nascentes (PROMOTORIA DE JUSTIÇA DA COMARCA DE RIALMA - GOIÁS, 2010).

O juiz da comarca solicita ao diretor da usina informações, o mais breve possível, quanto à finalização, da obra de ampliação e melhoria do ponto de 
captação de água da SAA de Ceres e Rialma, de responsabilidade da mesma, cujo prazo de conclusão se findou em 14/08/2009.

Observa-se que o processo referente ao Rio das Almas da cidade de Rialma encontra-se ainda em andamento, quanto ao da cidade do Carmo do Rio Verde a indústria foi condenada na obrigação de fazer consistente em regar o anel viário de Carmo do Rio Verde, durante os dias em que utilizá-lo, por meio de caminhão pipa, em intervalos regulares e suficientes para que não seja produzida poeira, garantindo-se um mínimo de 06 (seis) regas diárias; tendo por objeto a presente ação uma obrigação de natureza infungível, seja na sentença de mérito aplicado as astreintes previstas no artigo 11 da Lei 7347/85 como forma de obrigar a ré a cumprir a obrigação.

\section{Atos praticados pela indústria e os requisitos da NBR ISO 14000}

As organizações não precisam de certificações como a NBR ISO 14000 para respeitar o meio ambiente e a sociedade, mas podem se espelhar nos seus princípios para evitarem problemas judiciais como os relacionados neste artigo. Os requisitos de um Sistema de Gestão Ambiental também ajudam as empresas a fazerem o seu Marketing Verde, conquistando assim a simpatia da sociedade. De acordo com Valle (2007) a ISO 14001 aponta requisitos que contemplam as políticas de prevenção, e de atribuição de qualidade extra nos processos e produtos.

Quadro 2 - Alguns requisitos do Sistema de Gestão Ambiental conforme NBR ISO 14001:2004 e os atos praticados pela indústria.

\begin{tabular}{|c|c|}
\hline Alguns Requisitos Gerais de SGA & Atos Praticados pela Indústria \\
\hline $\begin{array}{l}\text { Estabelecimento de política } \\
\text { apropriada. }\end{array}$ & $\begin{array}{l}\text { Inexistência de Política Ambiental apropriada, } \\
\text { comprovada por denúncias do Ministério Público. }\end{array}$ \\
\hline $\begin{array}{l}\text { Análise dos impactos provocados referentes às } \\
\text { atividades produção. }\end{array}$ & $\begin{array}{l}\text { Destruição de mata ciliar e de reserva permanente, } \\
\text { extração de recursos hídricos sem a devida } \\
\text { outorga por órgão competente comprovada por } \\
\text { denúncias do Ministério Público. } \\
\text { Aspersão de poeira, provocando transtornos para } \\
\text { população e danos a saúde comprovada por } \\
\text { denúncias do Ministério Público. }\end{array}$ \\
\hline $\begin{array}{lcccc}\text { Estabelecimento de } & \text { objetivos } & \text { e } & \text { metas } \\
\text { ambientais apropriadas. } & & & \end{array}$ & $\begin{array}{l}\text { Objetivos e metas sem comprometimento } \\
\text { ambiental comprovada por denúncias do Ministério } \\
\text { Público. }\end{array}$ \\
\hline $\begin{array}{l}\text { Atividades de planejamento ambiental, controle, } \\
\text { monitoramento, ação preventiva e corretiva, } \\
\text { auditoria e análise. }\end{array}$ & $\begin{array}{l}\text { Inexistência desses requisitos ambientais } \\
\text { comprovada por denúncias do Ministério Público. }\end{array}$ \\
\hline
\end{tabular}

auditoria e análise.

Fonte: Barbieri (2008)

Elaboração: Dados elaborados pelo próprio autor/2012. 
Conforme os dados acima se percebem que os atos praticados pela empresa não são compatíveis e nem se aproximam com as normas da NBR ISO 14001, e a gravidade dessas não conformidades geraram denúncias e processos judiciais.

\section{CONSIDERAÇÕES FINAIS}

Relacionando a literatura existente sobre sistemas empresariais e meio ambiente, como também compreendendo os passivos ambientais gerados pela indústria sucroalcooleira instalada na microrregião de Ceres-GO, constata-se, que em alguns casos o crescimento econômico não acompanha o desenvolvimento social e muito menos contempla as questões emergentes de preservação ambiental.

O crescimento econômico é condição necessária, porém, não é suficiente para que efetivamente ocorra um desenvolvimento sustentável. Urge que não se degrade o meio ambiente e não se explore incontrolavelmente os recursos naturais que são limitados. Por isso, cresce em países desenvolvidos e em desenvolvimento a consciência ambiental. A sociedade preocupa-se com a preservação e proteção da natureza. Não se admite uma produção que destrói ou degrada a biodiversidade, os rios, as matas ciliares, as fontes de água, polui o ar, agride a saúde dos seres humanos e de animais, os ecossistemas e toda e qualquer forma de vida que habita e mantém viva a mãe terra.

A consciência ambiental emergente mostra-se eficaz e consumidores lúcidos repudiam bens que ao longo do seu ciclo de produção causaram danos ao meio ambiente.

No discorrer do estudo verificou-se que os efeitos ambientais dos processos produtivos sucroalcooleiros estimulados pela expansão em Goiás e na Microrregião de Ceres (GO), que tiveram um elevado índice de expansão, contribuíram gradativamente para com os passivos ambientais, do qual uma empresa é acusada pelo ministério público, porque desmatou áreas de matas ciliares e instalou equipamentos para bombear água do Rio das Almas, na cidade de Rialma-GO, sem o consentimento legal e outorga de direitos para o uso de recursos hídricos. Foi passiva, também, de outra ação porque em razão de sua expansão utilizou com 
mais frequência uma estrada vicinal sem pavimentação asfáltica no município de Carmo do Rio Verde (GO), o que causou aspersão de poeira na atmosfera e trouxe danos à saúde da população. As ações movidas pelo Ministério Público, conforme consta nos termos literalmente transcritos, que a indústria não implantou uma política de gestão ambiental, que contempla questões socioambientais e assim produziu transtornos e prejuízos à natureza e à saúde da população local.

Um sistema empresarial não precisa ser certificado pela série ISO 14000, para respeitar as leis e as questões ambientais, mas pode-se utilizar das suas diretrizes como inspirações nos processo produtivos, pois futuramente o mercado mais exigente somente poderá adquirir produtos de empresas certificadas por uma norma, no entanto, gestores que a utilizam como inspiração em políticas de produção, terão mais facilidade de enquadrar as suas empresas nas exigências de certificações e processos.

Verifica-se que a certificação ambiental favorece a empresa em todas as formas, melhora a imagem que o público possui da empresa, e passa a ser um diferencial de competitividade, por desenvolver oportunidades de negócio, por meio da imagem verde/limpa criada pelos clientes.

Sabe-se, que o Sistema de Gestão Ambiental (SGA) é um passo bastante extenso em direção à redução dos efeitos ambientais, decorrentes de seus procedimentos de produção. Salienta-se, contudo, que procedimentos isolados, dispersos de um SGA, colaboram, para que se alcance um desenvolvimento sustentável, mas não garantem a aquisição da certificação.

A empresa pesquisada não possui certificação ambiental, e respondeu a duas ações movidas pelo Ministério Público em duas cidades (Rialma e Carmo do Rio Verde). A indústria foi acusada de causar danos ambientais, como também danos à saúde dos moradores que residem às margens e adjacências de uma estrada vicinal não pavimentada no qual transitam caminhões de transporte de cana. O processo de Rialma ainda está em andamento e o de Carmo do Rio Verde a organização acatou a determinação da justiça na época.

Por fim, conclui-se que a usina deve reconhecer os danos provocados ao meio ambiente e repará-los, atendendo a sentença a ser proferida pela justiça na ação movida pelo Ministério Público, ainda, em pendência.

\section{REFERÊNCIAS}


ABNT. Novas normas ambientais. 2005. Disponível em: http://www.tresiambiental.com.br/article.php3?id article=255. Acesso em: 07/05/2012.

ALEGRIA, M. A Gestão empresarial cada vez mais verde. 2009. Disponível em www.revistameioambiente.com.br/page/7/?s=sustentáveis. Acesso em: 25/01/2012.

ANTUNES, R. Riqueza e miséria do trabalho no Brasil. São Paulo : Boitempo, 2006.

BARBIERI, J.C. Gestão ambiental empresarial: conceitos, modelos e instrumentos. $2^{a}$.ed.atual e ampliada.-São Paulo: Saraiva,2008.

CANASAT - Mapeamento da cana via imagens de satélite de observação da Terra. INPE - Instituto Espacial de Pesquisas Espaciais. 2011. Disponível em: http://www.dsr.inpe.br/canasat/. Acesso em: 07/05/2012.

em 09/06/2012.

Disponível e: http://www.dsr.inpe.br/laf/canasat/cultivo.html. 2011. Acesso

CONAB - Companhia Nacional de Abastecimento. Acompanhamento de safra brasileira: cana-de-açúcar, primeiro levantamento, abril/2012 - Companhia Nacional de Abastecimento. - Brasília: Conab 2012.

CONAB - Companhia Nacional de Abastecimento. Acompanhamento de safra brasileira: cana-de-açúcar, primeiro levantamento, abril/2012 - Companhia Nacional de Abastecimento. - Brasília: Conab 2009.

CORDEIRO, J. V B. de Mello; RIBEIRO, R. Vieira. Gestão da Empresa. 2002. Disponível em http://www.fae.edu/publicacoes/pdf/empresarial/1.pdf. Acesso em: 22/05/2011.

COPOLA, G. A Lei dos Crimes Ambientais, Comentada Artigo por Artigo. 2005. Disponível em http://pt.scribd.com/doc/71922914/Lei-9605-98-Comentada. Acesso em 14/05/2012.

DIAS, E. P. Conceitos de Gestão e Administração: Uma Revisão Crítica. 2002. Disponível em http://www.facef.br/rea/edicao01/ed01 art01.pdf. Acesso em: 22/05/2011.

FURTADO, Ricardo Cavalcanti; FURTADO, Maria de Fátima de Gusmão. A Gestão Empresarial e o Meio Ambiente. 2010. Disponível em: www.fag.edu.br Acesso em: 03/05/2011.

JUCOVSKY, V. L. R. S. O Papel do Juiz na Defesa do Meio Ambiente. Revista de Direito Ambiental, no 19, p. 41-52. 2000.

KRAEMER, M.E.P. Passivo Ambiental. 2004. Disponível em http://www.sense8.com.br/clientes/amda/imgs/up/Artigo 21.pdf. Acesso em: 15/08/2012.

MACHADO, P.A.L.Direito Ambiental Brasileiro. 10.ed. rev. atual e ampl. São Paulo: Malheiros Editores, 2008.

MARCONI, Maria de Andrade; LAKATOS, Eva Maria. Fundamentos de metodologia científica. 5. ed. São Paulo: Atlas, 2003. 
MOURA, L. A. A. - Qualidade e Gestão Ambiental: Sugestões para Implantação das Normas ISO 14000 nas Empresas. São Paulo: Editora Oliveira Mendes, 2005.

PALHANO, E; MAFRA, E. Crimes Ambientais no Rio Grande do Norte. 2005. Disponível em http://fiscalambiental.files.wordpress.com/2012/04/crimes-ambientaisno-rn.pdf. Acesso em: 05/05/2012.

PROMOTORIA DE JUSTIÇA DA COMARCA DE RIALMA - GOIÁS. Excelentíssimo Senhor Juiz de Direito da Vara Única da Comarca de RIALMA/GO. 2009.

PROMOTORIA DE JUSTIÇA DA COMARCA DO CARMO DO RIO VERDE - GOIÁS. Excelentíssimo Senhor Juiz de Direito da Comarca de Carmo Do Rio Verde Goiás. 2006.

RICHARDSON, R. J. Pesquisa social, métodos e técnicas. 3 ed., rev. e ampl., São Paulo: Atlas, 1999.

SANTOS, et al. Influência da utilização de aditivos químicos no perfil da fermentação, no valor nutritivo e nas perdas de silagens de cana-deaçúcar. Revista Brasileira de Zootecnia, v.37, n.9, p.1555-1563, 2008.

SILVA, A. A.; MIZIARA, F. A expansão da fronteira agrícola em Goiás e a localização das usinas de cana de açúcar. Revista Pesquisa Agropecuária Tropical, v.41 n.3, 2011. (no prelo).

SOUZA, Cleonice Borges de e MIZIARA, Fausto. Políticas de Financiamento À Expansão do Setor Sucroalcooleiro Em Goiás Versus Políticas Ambientais. 2010

TIBOR, T. e I. FELDMAN. ISO 14000: Um Guia para as Novas Normas de Gestão Ambiental - São Paulo: Futura, 2000.

TOLEDO, M.L. Ministério Público do Estado de Goiás - Promotoria de Justiça de Carmo do Rio Verde. 2006. Disponível em http://www.mp.go.gov.br/portalweb/hp/g/docs/poluicao do ar - poeira.pdf. Acesso em: 09/03/2012.

TRIVIÑOS, A. N. S. Introdução à pesquisa em Ciências S ociais: a pesquisa qualitativa em educação. São Paulo: Atlas, 1987.

VALLE, C. E. Como se Preparar para as Normas ISO 14000: Qualidade Ambiental - $2^{a}$ Edição. São Paulo: Pioneira, 2007.

ZURITA, M. L. L. Modelo de sistema de Gestão ambiental Municipal em Conformidade com os Requisitos Estabelecidos pelas normas da Série ISSO 14000. $2004 . \quad$ Disponível em http://www.lume.ufrgs.br/bitstream/handle/10183/6035/000479656.pdf?sequence=1. Acesso em: 12/04/2011. 